\title{
Palmitoylethanolamide in Fibromyalgia: Results from Prospective and Retrospective Observational Studies
}

\author{
Rosaria Del Giorno · Stephen Skaper · Antonella Paladini • \\ Giustino Varrassi $\cdot$ Stefano Coaccioli
}

To view enhanced content go to www.paintherapy-open.com Received: June 26, 2015 / Published online: September 3, 2015

(C) The Author(s) 2015. This article is published with open access at Springerlink.com

\begin{abstract}
Introduction: Fibromyalgia syndrome (FM) is characterized by persistent pain which is often refractory to common analgesic therapies and is particularly disabling. The objective of this study was to evaluate the therapeutic efficacy of duloxetine (DLX) + pregabalin (PGB) in patients suffering from FM and the possible added benefit of the lipid signaling molecule,
\end{abstract}

Electronic supplementary material The online version of this article (doi:10.1007/s40122-015-0038-6) contains supplementary material, which is available to authorized users.

R. Del Giorno $(\varangle) \cdot$ S. Coaccioli

Institute of Internal Medicine, Rheumatology and Medical Therapy of Pain, Perugia University, District of Terni, Perugia, Italy

e-mail: delgiornorosaria@yahoo.it

\section{S. Skaper}

Department of Pharmaceutical and Pharmacological Sciences, Padua University, Padua, Italy

A. Paladini

Institute of Anesthesiology and Pain Therapy,

L'Aquila University, L'Aquila, Italy

G. Varrassi

Paolo Procacci Foundation, L'Aquila University, L'Aquila, Italy

G. Varrassi · S. Coaccioli

European League Against Pain, Zürich, Switzerland palmitoylethanolamide (PEA). PEA is well-documented to exert anti-inflammatory, analgesic, and pain-relieving effects at both the preclinical and clinical level.

Methods: A total of 80 patients were recruited in two steps. The first was a retrospective observational study comprising 45 patients. This patient group received DLX + PGB for 6 months. The second step was a prospective observational study with 35 patients. Patients in this cohort began treatment with DLX + PGB at the same dosage as for the retrospective study plus micronized PEA (PEA-m ${ }^{\circledR}$; Epitech Group, Italy) and ultramicronized PEA (PEA-um ${ }^{\circledR}$; Epitech Group, Italy) for 3 months. Positive tender points (TPs), pain evoked, and pain intensity were evaluated at baseline and after 3 and 6 months in both studies. Statistical analyses were employed for comparison of data within the two studies and between them.

Results: The retrospective observational study (DLX + PGB), after 3 months of treatment showed a decrease of positive TPs, pain evoked, and pain intensity. After 6 months of treatment, these parameters had further improvement. In the prospective observational study $(\mathrm{DLX}+\mathrm{PGB}+\mathrm{PEA}), \quad$ PEA introduction after 
3 months of therapeutic regimen with DLX + PGB provided a significant improvement in pain symptoms, with a further reduction in the number of TPs and significant reduction in pain, compared to combined DLX + PGB only $(p<0.0001$ for TPs and Visual Analog Scale comparisons). None of the patients experienced adverse side effects.

Conclusion: Our study confirms the efficacy of DLX + PGB and demonstrates as well the added benefit and safety of PEA in the treatment of pain in patients affected by FM.

Keywords: Chronic pain; Duloxetine; Fibromyalgia; Multimodal therapy; Pain; Palmitoylethanolamide; Pregabalin

\section{INTRODUCTION}

Fibromyalgia syndrome (FM) is a very prevalent rheumatic disease. Widely underestimated and rarely diagnosed, it strikes between 2 and $4 \%$ of the general population [1], with a clear predominance in females. In Italy, disease prevalence is $4.1 \%$ in the general population (6.9\% in women and $0.3 \%$ in men) [1]. FM shows a bimodal pattern of incidence: a first peak between 25 and 35 years and a second between 45 and 55 years [2]. This syndrome is characterized by widespread chronic pain, tenderness in muscles and deep tissues, and fatigue accompanied by other non-specific symptoms, including sleep disturbances. In particular, the widespread pain of $\mathrm{FM}$ is a disabling condition and can become quite marked when evoked by digital pressure at tender points (TPs). Research suggests that pain in FM syndrome is associated with a generalized alteration in the central somatosensory system $[3,4]$. Central sensitization is likely sustained by neuroinflammatory processes triggered by microglia activation [5]. These data suggest that the cross-talk between nervous and immune systems plays a fundamental role in the onset and progression of chronic pain in patients with FM [6].

Diagnosis is still carried out according to criteria developed in 1990 by the American College of Rheumatology (ACR-90 criteria): a history of widespread musculoskeletal pain lasting at least 3 months and the presence of at least 11 of 18 predefined TPs [7]. Nevertheless, the criteria of the ACR for FM of 2010 are increasingly applied [8], consisting of 2 scales: the Widespread Pain Index (WPI) and the Symptom Severity (SS) scale. Numerous other symptoms accompany the clinical course and daily life of patients with FM: asthenia and decreased muscle strength [9], headache, irritable bowel syndrome, paresthesias, cramps and fasciculations, cognitive disorders, anxiety-depressive syndrome, blurred vision, and unusual thermal, tactile, auditory, visual and/or olfactory sensations [10, 11]. Although trigger conditions such as strong psycho-physical stress [12, 13] or febrile illness (often of viral origin) have been suggested, the pathogenesis of FM remains largely unknown. Several hypotheses have been advanced, which have led to the definition of FM as a neuroimmune-endocrine disorder, whereby the molecular mechanisms of neurotransmitter dysfunction are associated with more obvious neurological deficits [10, 14-20].

The etiopathogenic and clinical complexity of FM requires a multidisciplinary approach based on multimodal therapeutic strategies that include also non-pharmacological interventions [10, 14]. In particular: reduce peripheral nociceptive input (muscle relaxants, anti-inflammatory agents, physical therapy); reduce or prevent central sensitization; treat co-morbid conditions that contribute to 
maintaining a high pain threshold [17]. At present, treatment of FM favors the use of centrally acting anti-epileptics and antidepressants, since drugs acting peripherally (e.g., corticosteroids, non-steroidal anti-inflammatory drugs) would be less effective [21]. Anti-epileptics such as gabapentin and pregabalin (PGB) have been used in FM with especially encouraging results: $30 \%$ reduction in pain intensity in about half of patients and 50\% in about one-third [22]. Further, PGB was effective in persistent pain refractory to common analgesics and sleep disorders [23]. Antidepressants, by improving the quality-quantity of sleep, can decrease some associated symptoms such as fatigue and gastrointestinal disorders, thereby contributing to the optimization of analgesia in patients with FM [24]. Among antidepressants, inhibitors of serotonin/norepinephrine reuptake (e.g., duloxetine [DLX]) were more efficacious than serotonin reuptake inhibitors [25, 26]. Optimal results were achieved by integrating treatments to take advantage of potential drug synergism while assuring a better safety profile, owing to the use of each drug at its lowest effective dose [27].

An important advance in the field of analgesic treatment for many chronic painful conditions is represented by $\mathrm{N}$-(2-hydroxyethyl) esadecanamide (palmitoylethanolamide or PEA) [28], a member of the naturally occurring family of fatty acid amides. While initially recognized for its anti-inflammatory activity, PEA is today viewed as a key element of the body's endogenous mechanism to maintain/restore homeostatic balance in the face of different types of damage, including activation of the inflammatory response and nociceptive pathways. There is increasing evidence that PEA acts as mediator of resolution of inflammatory processes, thus counteracting the progression of chronic inflammation: it is synthesized/metabolized by microglia and mast cells; it down-modulates mast cell and microglia activation; and tissue levels of PEA are alterated in brain areas involved in nociception following neuropathic pain induction, as well as conditions associated with injury to nervous tissue (stroke, spinal cord injury) [29, 30]. The mechanism of PEA action has been defined by the acronym ALIA (Autacoid Local Injury Antagonism) [31]. PEA is effective in the treatment of chronic pain caused by different etiopathogeneses [32] suggesting activation of non-neuronal cells (mast cells and glia) as a common factor in the various pathological conditions [33-35]. Based on its effectiveness, lack of drug interactions and absence of adverse effects [30], PEA represents a promising and innovative therapeutic strategy, especially if placed within a multimodal pharmacotherapy.

The above findings encouraged us to evaluate PEA effects in patients with FM. Our investigation was devised so as to include two separate studies: a retrospective observational study and a prospective uncontrolled study. The first was intended to assess efficacy and safety of DLX + PGB association in controlling patient pain, while the second was to determine whether micronized PEA (PEA-m ${ }^{\circledR}$; Epitech Group, Italy) and ultramicronized PEA $\left(\right.$ PEA-um ${ }^{\circledR}$; Epitech Group, Italy) would provide additional clinical benefit over and above to the results obtained with DLX + PGB. As compared to naïve PEA (particle size profile ranging between 100 and $700 \mu \mathrm{m})$, micronized and ultramicronized PEA differs in their particles size profile $(2-10 \mu \mathrm{m}$ and $0.8-6 \mu \mathrm{m}$ at most, respectively). Micronization and ultramicronization processes yield a different crystalline structure with higher energy content and smaller particle size which result in better diffusion and distribution of these molecules 
compared to the naïve form, and thus superior biological efficacy $[30,36]$. The study aim was to investigate, whether PEA-m and PEA-um would provide additional clinical benefit in controlling pain in patients with FM, in multimodal therapy.

\section{METHODS}

The complete study was conducted on a total of 80 patients with FM, divided into two separate arms, as described below. Patients were recruited within the Medical Clinic at the University of Perugia General Hospital "Santa Maria" of Terni. All patients provided informed written consent to participate. This study was carried out in accordance with the Helsinki Declaration of 1964, as revised in 2013, and Good Clinical Practice and was approved by The Local Ethical Committee of Umbria.

\section{Retrospective Observational Study}

Patients with a diagnosis of FM according to the ACR criteria were selected in this step through their clinical charts. All patients were referred to the Ambulatory of Rheumatology outpatients clinic of the Santa Maria General Hospital of Terni and were treated with different combination therapy (DLX + PGB) for 6 months.

\section{Prospective Uncontrolled Study}

Patients with a diagnosis of FM according to the ACR criteria were enrolled. PEA-um and PEA-m were added at the third month of this existing therapeutic regimen based on DLX + PGB, for a total duration of 3 months (PEA-um tablets $600 \mathrm{mg} / \mathrm{bid}$ in the first month, and PEA-m tablets $300 \mathrm{mg} / \mathrm{bid}$ in the next 2 months).
Patients were selected based on their superimposability in terms of number and therapeutic doses to those enrolled in the retrospective observational study.

In all patients, the main outcomes were TPs and Visual Analog Scale (VAS). In both steps of the study (retrospective and prospective), a qualified rheumatologist performed the TP examination in a standardized way. The examiner used exactly the same instructions for each subject and used a dolorimeter with a pressure of $4 \mathrm{~kg} / \mathrm{cm}^{2}$ to ensure equivalence in application of pressure to the TPs. VAS, from $0=$ no pain to $10=$ the worst pain, was used to measure pain score.

\section{Statistical Analysis}

A multivariate analysis generalized linear mixed model (GLMM) was carried out to test whether the clinical benefit of PEA was independent of ongoing treatment with DLX + PGB. Gender, treatment, time, and interaction time "treatment" were used as covariate to test the efficacy. Single comparison was evaluated using Tukey-Kramer adjusted test.

\section{RESULTS}

\section{Retrospective Observational Study}

In this step, we analyzed 45 patients (37 women, 8 men; mean age $47 \pm 5$ years, range $40-52$ years). At baseline, the patients showed the following characteristics: number of positive TPs equal to $14 / 18$ with presence of evoked pain in $3 / 3$ and intensity of pain on the VAS was equal to $6.9 \pm 0.09$. They received a combination therapy comprising DLX + PGB. The mean daily dose of DLX was $39.3 \mathrm{mg} /$ day [30 mg/day (31 patients) and $60 \mathrm{mg} /$ day (14 
patients)]; the mean daily dose of PGB was $47.2 \mathrm{mg} /$ day $\quad[25 \mathrm{mg} /$ day $\quad(15$ patients $)$, $50 \mathrm{mg} /$ day (20 patients), and $75 \mathrm{mg} /$ day (10 patients); Table 1]. After 3 months of therapy with DLX + PGB, the positive TPs decreased from $14 / 18$ to $8 / 18$, the presence of evoked pain diminished from $3 / 3$ to $1 / 3$, and the VAS scale mean score went from $6.9 \pm 0.09$ to $4.0 \pm 0.11$. After 6 months of therapy, evoked pain remained at $1 / 3$, positive TPs were further reduced to $4 / 18$, and the VAS scale mean score reached the value of $3.0 \pm 0.12$.

\section{Prospective Observational Study}

The patient baseline characteristics were: number of positive TPs equal to $14 / 18$ with presence of evoked pain in $3 / 3$ and intensity of

Table 1 Clinical characteristics of the study populations

\begin{tabular}{lll}
\hline Characteristics & Retrospective study & Prospective study \\
\hline Number & 45 & 35 \\
Gender, $n$ & & \\
Male & 8 & 5 \\
Female & 37 & 30 \\
Age, years & & \\
Mean \pm SD & $47 \pm 5$ & $48 \pm 5$ \\
Range & $40-52$ & $42-53$ \\
VAS, mean \pm SE & & \\
Baseline (ref.) & $6.9 \pm 0.09$ & $6.6 \pm 0.15$ \\
Third month & $4.0 \pm 0.11^{*}$ & $3.7 \pm 0.17^{*}$ \\
Sixth month & $3.0 \pm 0.12^{*}$ & $1.9 \pm 0.17^{* *}$ \\
Positive TPs/18, mean \pm SE & & $13.8 \pm 0.28$ \\
Baseline (ref.) & $13.5 \pm 0.33$ & $7.6 \pm 0.19^{*}$ \\
Third month & $8.0 \pm 0.17^{*}$ & $1.0 \pm 0.14^{*}$ \\
Sixth month & $4.2 \pm 0.18^{*}$ & 300 bid (months 2-3) \\
Therapy & & 36.0 \\
DLX, mg/day (average) & 39.3 & 49.2 \\
PGB, mg/day (average) & 47.2 & 600 bid (month 1$)$ \\
PEA-m/PEA-um, mg & & \\
\hline aid & - & \\
& &
\end{tabular}

bid Twice daily, DLX Duloxetine, PEA Palmitoylethanolamide, PGB Pregabalin; SD Standard deviation, SE Standard error, $T P s$ Tender points, $V A S$ Visual analog scale

${ }^{*} p<0.05$ vs previous evaluation, ${ }^{* *} p<0.0001$ vs previous evaluation

${ }^{a}$ Added at third month in the prospective study 


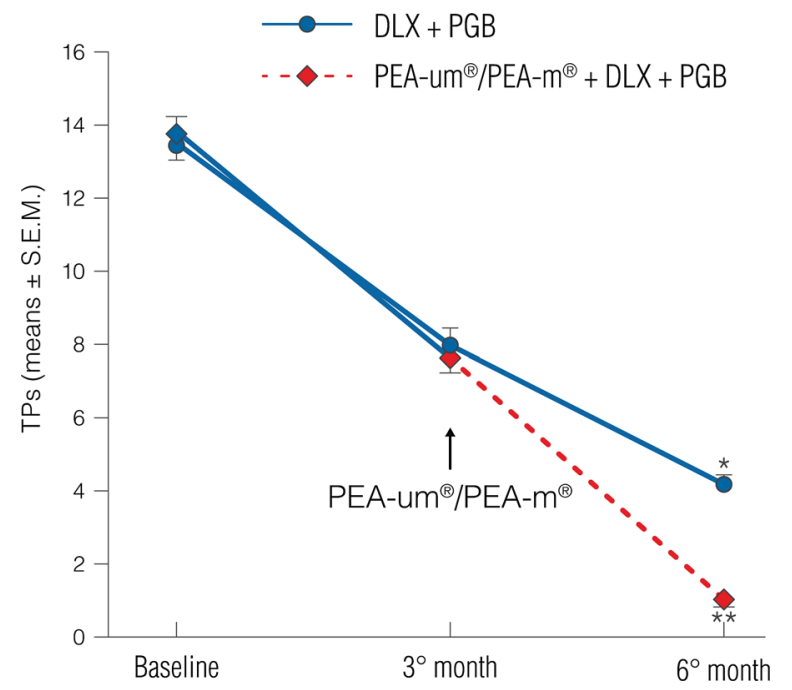

Fig. 1 Reduction in number of positive tender points. Retrospective group (circle with continuous line): patients received DLX + PGB from baseline to sixth month. Number of TPS reduction was statistically significant ${ }^{*} p<0.05$. Prospective group (square with continuous line): patients received DLX + PGB from baseline to third month. PEA-um/PEA-m was added to DLX + PGB (square with discontinuous line) from third to sixth month. Number of TPS reduction was statistically significant ${ }^{* *} p<0.0001$. DLX duloxetine, PEA-m micronized palmitoylethanolamide, $P E A-m$ ultramicronized palmitoylethanolamide, $P G B$ Pregabalin, TPs tender points

pain on the VAS scale equal to $6.6 \pm 0.15$. They were treated with PGB + DLX for three months; the DLX mean dose was $36 \mathrm{mg} /$ day [30 $\mathrm{mg}$ /day (24 patients) and $60 \mathrm{mg} /$ day (11 patients)]; the PGB mean dose was $49.2 \mathrm{mg} /$ day [25 mg/day (12 patients), $50 \mathrm{mg} /$ day (12 patients), and $75 \mathrm{mg} /$ day (11 patients)]. At the third month of this existing therapeutic regimen, PEA-um and PEA-m were added for a total duration of 3 months (tablets $600 \mathrm{mg} / \mathrm{bid}$ in the first month and tablets $300 \mathrm{mg} / \mathrm{bid}$ in the next 2 months; Table 1). After 3 months of therapy with $\mathrm{DLX}+\mathrm{PGB}+\mathrm{PEA}-\mathrm{um}$ and PEA-m, the number of positive TPs was $1 / 18$ (Fig. 1), the evoked pain was equal to $1 / 3$ and the VAS scale mean score diminished down from $3.7 \pm 0.17$ (month 3 ) to $1.9 \pm 0.17$ (month 6) (Fig. 2). The effects of the combination therapy DLX + PGB + PEA-um

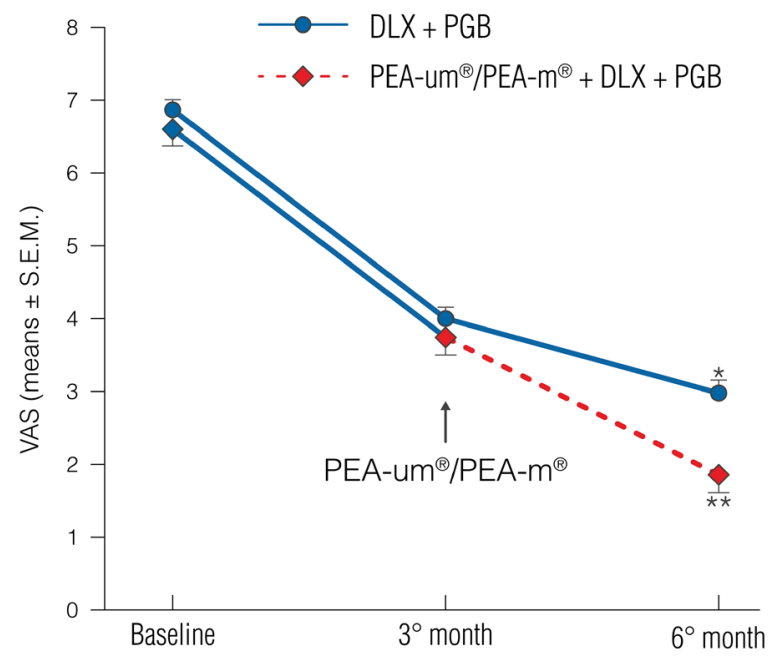

Fig. 2 Reduction in pain intensity by VAS measurement. Retrospective group (circle with continuous line): patients received DLX + PGB from baseline to sixth month. VAS reduction was statistically significant ${ }^{*} p<0.05$. Prospective group (square with continuous line): patients received DLX + PGB from baseline to third month. PEA-um/ PEA-m was added to DLX + PGB (square with discontinuous line) from third to sixth month. VAS reduction was statistically significant ${ }^{* *} p<0.0001 . D L X$ duloxetine, PEA- $m$ micronized palmitoylethanolamide, PEA- $m$ ultramicronized palmitoylethanolamide, $P G B$ Pregabalin, $V A S$ Visual Analog Scale

and PEA-m achieved significance $(p<0.0001)$ for VAS and TPs comparisons (Table 2). In the analysis of variance, all included variables were significant. The addition of PEA to the therapy with DLX + PGB provided a significant clinical benefit independent of concomitant therapies The VAS continually decreased over time; the difference between treated and controls was largest at month 6 ( $p<0.0001$; Fig. 2$)$. None of the study patients discontinued therapy before the end of the treatment period because they did not experience either systemic/local adverse events or intolerance to PEA.

\section{DISCUSSION}

One of the most noteworthy clinical features of FM is widespread pain that, at particular points 
Table 2 Generalized linear mixed model analysis of tender points

\begin{tabular}{llrr}
\hline & $\begin{array}{l}\text { Change between } \\
\text { DLX + PGB group and }\end{array}$ & Standard error & $\boldsymbol{p ~ v a l u e}^{*}$ \\
& $\begin{array}{l}\text { PEA + DLX + PGB } \\
\text { group }\end{array}$ & & \\
\hline After 3 months & 0.3461 & 0.2613 & 0.7705 \\
After 6 months & 3.1461 & 0.2458 & $<0.0001$ \\
\hline
\end{tabular}

DLX Duloxetine, PEA Palmitoylethanolamide, PGB Pregabalin

${ }^{*}$ Adjusted by Tukey-Kramer for multiple comparisons

called TPs, can reach very high levels when provoked by pressure [1]. Centrally acting anti-epileptics and antidepressants have proven beneficial in reducing pain intensity in patients with FM, although their effects leave much to be desired. Inflammation is a key feature of chronic and neuropathic pain [33]. A major advance in our understanding of the pathogenic mechanisms underlying FM, as well as other chronic pain syndromes with important therapeutic consequences, is knowledge about the physiological role played by the body's 'built in' mechanisms for resolution of inflammation [34]. We are coming to appreciate the importance of PEA as an 'on demand' molecule produced to restore homeostatic balance against stress and tissue injury [34]. Initially studied for its anti-inflammatory activity, PEA is now considered to be at the center of these endogenous mechanisms of protection. This fatty acid amide down-modulates mast cell degranulation and the consequent release of pro-inflammatory mediators, as well as the pro-algogenic actions of other immune-related non-neuronal cells such as microglia-effects likely to account for its pain-relieving qualities. Indeed, several studies have demonstrated the pain-relieving efficacy of PEA irrespective of etiology, suggesting a common cellular denominator in its mode of action [31, 32].
PEA anti-inflammatory and pain-relieving properties have been amply demonstrated in a number of animal models [30, 37, 38]. In humans, PEA is highly efficacious in the treatment of chronic pain associated with different diseases [32, 39-42] and has no deleterious side effects at pharmacologically effective doses.

The main limitation of this exploratory study is the open-label design without a randomization and blinding. Therefore, it is not possible to ascertain the extent to which improvements with combination therapy may have been due to patient or investigator expectations. Moreover, it should be considered that, when this study was conducted, there were no available data on the combination of PEA + PGB on FM outcomes. Therefore, this was designed as an exploratory study to evaluate the potential effects of a multimodal pharmacotherapy in FM. The study results offer some clinical information regarding the potential benefits of adding PEA to DLX + PGB in patients with FM, indicating the need for further research into combinations with different drug classes. Again, further studies would need to be conducted to evaluate the benefits of combining these treatments in the general FM population.

Our research suggests the efficacy and safety of PEA in the treatment of pain associated with 
FM. Its introduction in the therapeutic regimen of DLX + PGB provided a significant improvement in pain symptoms, with a further reduction in the number of TPs and significant reduction in pain, compared to combined DLX + PGB only. It is interesting to note that the results achieved in 3 months with PEA-um and PEA-m added to therapeutic regimen are significantly better than those after 6 months of DLX + PGB only, and that this improvement appeared to depend on PEA. Given its effectiveness, lack of drug-drug interactions, and absence of adverse events, PEA-um and PEA-m may be a promising therapeutic strategy for the treatment of FM and other disorders with chronic pain, especially if utilized in the context of a multimodal pharmacotherapy.

\section{CONCLUSIONS}

The results from this open-label, non-randomized, non-blinding clinical study suggest that adding PEA to initial PGB + DLX therapy improved the outcome of FM. For some patients requiring more than one FM medication, the addition of PEA may be a favorable treatment option. Again, further studies would need to be conducted to evaluate the benefits of combining these treatments in the general FM population.

\section{ACKNOWLEDGMENTS}

This study was carried out under the patronage of the Italian Association for the Study of Pain (AISD), the Paolo Procacci Foundation (PPF), and the European League Against Pain. All named authors meet the International Committee of Medical Journal Editors (ICMJE) criteria for authorship for this manuscript, take responsibility for the integrity of the work as a whole, and have given final approval to the version to be published. The Authors thank Dr. Carlo Schievano for the statistical analysis and Ms. Marta di Felice for her excellent secretarial work. No funding or sponsorship was received for this study or publication of this article.

Conflict of interest. Rosaria Del Giorno, Stephen Skaper, Antonella Paladini, Giustino Varrassi, and Stefano Coaccioli have nothing to disclose regarding the publication of this article.

Compliance with ethics guidelines. All procedures followed were in accordance with the ethical standard of the responsible committee on human experimentation (institutional and national) and with the Helsinki Declaration of 1964, as revised 2013. The study was approved by The Local Ethical Committee of Umbria.

Open Access. This article is distributed under the terms of the Creative Commons Attribution-NonCommercial 4.0 International License (http://creativecommons.org/licenses/ by-nc/4.0/), which permits any noncommercial use, distribution, and reproduction in any medium, provided you give appropriate credit to the original author(s) and the source, provide a link to the Creative Commons license, and indicate if changes were made.

\section{REFERENCES}

1. Queiroz LP. Worldwide epidemiology of fibromyalgia. Curr Pain Headache Rep. 2013;17(8):356.

2. Todesco S, Gambari PF, Punzi L. Malattie reumatiche. IV ed. Milano: McGraw-Hill; 2007.

3. Kim J, Loggia ML, Cahalan CM, et al. The somatosensory link in fibromyalgia: functional 
connectivity of the primary somatosensory cortex is altered by sustained pain and is associated with clinical/autonomic dysfunction. Arthritis Rheumatol Hoboken NJ. 2015;67(5):1395-405.

4. Napadow V, Harris RE. What has functional connectivity and chemical neuroimaging in fibromyalgia taught us about the mechanisms and management of "centralized" pain? Arthritis Res Ther. 2014;16(5):425.

5. Romero-Sandoval EA, Sweitzer S. Nonneuronal central mechanisms of pain: glia and immune response. Prog Mol Biol Transl Sci. 2015;131:325-58.

6. Staud R. Cytokine and immune system abnormalities in fibromyalgia and other central sensitivity syndromes. Curr Rheumatol Rev. 2015;11(2):109-15.

7. Wolfe F, Smythe HA, Yunus MB, et al. The American College of Rheumatology 1990 criteria for the classification of fibromyalgia. Report of the Multicenter Criteria Committee. Arthritis Rheum. 1990;33(2):160-72.

8. Wolfe F, Clauw DJ, Fitzcharles M-A, et al. Fibromyalgia criteria and severity scales for clinical and epidemiological studies: a modification of the ACR Preliminary Diagnostic Criteria for Fibromyalgia. J Rheumatol. 2011;38(6):1113-22.

9. Dombernowsky $\mathrm{T}$, Dreyer L, Bartels EM, Danneskiold-Samsøe B. Muscular strength in patients with fibromyalgia. A literature review. Ugeskr Laeger. 2008;170(4):217-24.

10. Mease P. Fibromyalgia syndrome: review of clinical presentation, pathogenesis, outcome measures, and treatment. J Rheumatol Suppl. 2005;75:6-21.

11. Clauw DJ. Fibromyalgia: a clinical review. JAMA. 2014;311(15):1547-55.

12. Sommer C, Häuser W, Gerhold K, et al. Etiology and pathophysiology of fibromyalgia syndrome and chronic widespread pain. Schmerz Berl Ger. 2008;22(3):267-82.

13. Tavel ME. Somatic symptom disorders without known physical causes: one disease with many names? Am J Med. 2015;. doi:10.1016/j.amjmed. 2015.04.041.

14. Coaccioli S, Varrassi G, Sabatini C, Marinangeli F, Giuliani M, Puxeddu A. Fibromyalgia: nosography and therapeutic perspectives. Pain Pract Off J World Inst Pain. 2008;8(3):190-201.
15. Dell'Osso L, Arnold L, Baroni S, et al. The inflammatory hypothesis of mood spectrum broadened to fibromyalgia and chronic fatigue syndrome. Clin Exp Rheumatol. 2014;33(1 Suppl 88):S109-16.

16. Rodriguez-Pintó I, Agmon-Levin N, Howard A, Shoenfeld Y. Fibromyalgia and cytokines. Immunol Lett. 2014;161(2):200-3.

17. Staud R, Rodriguez ME. Mechanisms of disease: pain in fibromyalgia syndrome. Nat Clin Pract Rheumatol. 2006;2(2):90-8.

18. Dedhia JD, Bone ME. Pain and fibromyalgia. Contin Educ Anaesth Crit Care Pain. 2009;9(5):162-6 (1).

19. Hawley DJ, Wolfe F. Pain, disability, and pain/ disability relationships in seven rheumatic disorders: a study of 1522 patients. J Rheumatol. 1991;18(10):1552-7.

20. Bergman S. Psychosocial aspects of chronic widespread pain and fibromyalgia. Disabil Rehabil. 2005;27(12):675-83.

21. Clauw DJ, Crofford LJ. Chronic widespread pain and fibromyalgia: what we know, and what we need to know. Best Pract Res Clin Rheumatol. 2003;17(4):685-701.

22. Moore RA, Wiffen PJ, Derry S, McQuay HJ. Gabapentin for chronic neuropathic pain and fibromyalgia in adults. Cochrane Database Syst Rev. 2011;3:CD007938.

23. Straube S, Derry S, Moore RA, Paine J, McQuay HJ. Pregabalin in fibromyalgia-responder analysis from individual patient data. BMC Musculoskelet Disord. 2010;11:150.

24. Häuser W, Bernardy $\mathrm{K}$, Uçeyler N, Sommer C. Treatment of fibromyalgia syndrome with antidepressants: a meta-analysis. JAMA. 2009;301(2):198-209.

25. Arnold LM. Duloxetine and other antidepressants in the treatment of patients with fibromyalgia. Pain Med Malden Mass. 2007;8(Suppl 2):S63-74.

26. Russell IJ, Mease PJ, Smith TR, et al. Efficacy and safety of duloxetine for treatment of fibromyalgia in patients with or without major depressive disorder: results from a 6-month, randomized, double-blind, placebo-controlled, fixed-dose trial. Pain. 2008;136(3):432-44.

27. Häuser W, Petzke F, Sommer C. Comparative efficacy and harms of duloxetine, milnacipran, and pregabalin in fibromyalgia syndrome. J Pain Off J Am Pain Soc. 2010;11(6):505-21. 
28. Kuehl FA, Jacob TA, Ganley OH, Ormond RE, Meisinger MAP. The identification of $\mathrm{N}$-(2-Hydroxyethyl)-Palmitamide as a naturally occurring anti-inflammatory agent. J Am Chem Soc. $1957 ; 79(20): 5577-8$.

29. Skaper SD, Facci L, Barbierato M, Zusso M, Bruschetta G, Impellizzeri D, et al. $\mathrm{N}$-Palmitoylethanolamine and neuroinflammation: a novel therapeutic strategy of resolution. Mol Neurobiol. 2015. doi:10.1007/ s12035-015-9253-8.

30. Skaper SD, Facci L, Fusco M, Della Valle MF, Zusso M, Costa B, et al. Palmitoylethanolamide, a naturally occurring disease-modifying agent in neuropathic pain. Inflammopharmacology. 2014;22(2):79-94.

31. Aloe L, Leon A, Levi-Montalcini R. A proposed autacoid mechanism controlling mastocyte behaviour. Agents Actions. 1993;39 Spec No:C145-7.

32. Gatti A, Lazzari M, Gianfelice V, Di Paolo A, Sabato E, Sabato AF. Palmitoylethanolamide in the treatment of chronic pain caused by different etiopathogenesis. Pain Med Malden Mass. 2012;13(9):1121-30.

33. Luongo L, Maione S, Di Marzo V. Endocannabinoids and neuropathic pain: focus on neuron-glia and endocannabinoid-neurotrophin interactions. Eur J Neurosci. 2014;39(3):401-8.

34. Tabas I, Glass CK. Anti-inflammatory therapy in chronic disease: challenges and opportunities. Science. 2013;339(6116):166-72.

35. Petrosino $\mathrm{S}$, Iuvone $\mathrm{T}$, Di Marzo $\mathrm{V}$. $\mathrm{N}$-Palmitoyl-ethanolamine: biochemistry and new therapeutic opportunities. Biochimie. 2010;92(6):724-7.
36. Impellizzeri D, Bruschetta $\mathrm{G}$, Cordaro $\mathrm{M}$, et al. Micronized/ultramicronized palmitoylethanolamide displays superior oral efficacy compared to nonmicronized palmitoylethanolamide in a rat model of inflammatory pain. J Neuroinflammation. 2014;11:136.

37. Freitag CM, Miller RJ. Peroxisome proliferator-activated receptor agonists modulate neuropathic pain: a link to chemokines? Front Cell Neurosci. 2014;8:238.

38. Miller RJ, Jung H, Bhangoo SK, White FA. Cytokine and chemokine regulation of sensory neuron function. Handb Exp Pharmacol. 2009;194:417-49.

39. Marini I, Bartolucci ML, Bortolotti F, Gatto MR, Bonetti GA. Palmitoylethanolamide versus a nonsteroidal anti-inflammatory drug in the treatment of temporomandibular joint inflammatory pain. J Orofac Pain. 2012;26(2):99-104.

40. Truini A, Biasiotta A, Di Stefano G, et al. Palmitoylethanolamide restores myelinated-fibre function in patients with chemotherapy-induced painful neuropathy. CNS Neurol Disord: Drug Targets. 2011;10(8):916-20.

41. Schifilliti C, Cucinotta L, Fedele V, Ingegnosi C, Luca S, Leotta C. Micronized palmitoylethanolamide reduces the symptoms of neuropathic pain in diabetic patients. Pain Res Treat. 2014;2014:849623.

42. Guida G, De Martino M, De Fabiani A, et al. La Palmitoiletanolamide (Normast $^{\circledR}$ ) en el dolor neuropático crónico por lumbociatalgia de tipo compresivo:estudio clinico multícéntrico. Dolor. 2010;25:35-42. 